\title{
Population Dynamics of Grayling: Modelling Temperature and Discharge Effects
}

\author{
S. Charles ${ }^{a 1}$, J.-P. Mallet ${ }^{b}$ and H. Persat ${ }^{c}$ \\ ${ }^{a}$ Laboratoire de Biométrie et Biologie Evolutive, UMR 5558 CNRS \\ University Lyon 1, 69622, Villeurbanne, France \\ ${ }^{b}$ ASCONIT Consultants, Espace Scientifique Tony Garnier, 69366 Lyon, France \\ ${ }^{c}$ Ecologie des Hydrosystèmes Fluviaux, UMR 5023, CNRS \\ University Lyon 1, 69622, Villeurbanne, France
}

\begin{abstract}
We propose a matrix population modelling approach in order to describe the dynamics of a grayling (Thymallus thymallus, L. 1758) population living in the Ain river (France). We built a Leslie like model, which integrates the climate changes in terms of temperature and discharge. First, we show how temperature and discharge can be related to life history traits like survival and reproduction. Second, we show how to use the population model to precisely examine the life cycle of grayling : estimated numbers of individuals at the beginning of the reproduction season, estimated number of individuals in summer, comparison between observed and simulated numbers of individuals. Finally, we discuss our results in the framework of the assessment of impact of possible climate changes on grayling populations.
\end{abstract}

Key words: matrix population modelling, riverine fish, Thymallus, temperature, discharge, climate change

AMS subject classification: 37N25, 39A05, 92D25, 92D40

\section{Introduction}

The study of population dynamics still faces basic experimental difficulties when applied to riverine fish, either at the individual or population levels. Indeed, it is hard to monitor such fish populations, either on field or even in laboratory. On field, a good monitoring of populations by,

\footnotetext{
${ }^{1}$ Corresponding author. E-mail: scharles@ biomserv.univ-lyon1.fr
} 
for example, annual electric fishing is made delicate due to the rather low efficiency of sampling in large rivers and the possible subsequent disturbance of both individuals and environment. In laboratory, this follow-up is only possible on the long term for the smallest species.

A modelling approach is an attractive alternative first to overcome such difficulties, by allowing investigations of a predictive nature, when one seeks for example to quantify the effect of climatic changes on the population dynamics; and second, to describe and/or explain biological phenomena as they are observed.

First motivated by the interrogations of the fishermen on the rarefaction of the species Thymallus thymallus in the lower river Ain, and despite those drawbacks mentioned above, we attempted to determine control factors in order to understand the grayling population dynamics. Although the grayling shows several of the characteristics having made the success of other salmonidae species (fast growth, halieutic and culinary values, laying and developments of young individuals in shallow waters), the grayling remained under-investigated in the literature until recently [13]. Several reasons can be identified for that: a limited geographical distribution, a delicate breeding and rearing in laboratory, and a habitat, consisting in a vast lotic systems, hard to prospect.

The grayling species is not regarded as in danger of extinction at the European scale, but many populations are often found isolated ones from the others, especially in river sections of short size and in an environment strongly influenced by anthropic activities. Biological integrity of these populations, as their persistence on the long term, can then be brought into play [14]. In previous works, we highlighted the effect of temperature on individual growth parameters [12]. We also showed in particular a significant increase in the annual average temperature (+ 1C between 1970's and 1990's) [11]. The grayling growth is thus currently faster than it was almost 30 years ago, except the years 1994 and 1995 during which the temperature exceeded the limit for growth (21C) over several weeks.

In this paper, we introduced a Leslie type matrix population model $[9,10]$, taking into account the effects of biotic and abiotic conditions, and their variations, on the grayling population dynamics in the Ain river.

\section{Biological background}

\subsection{Study area}

The Ain river which stretches over $190 \mathrm{~km}$, is a large tributary of the Rhne river entering it $20 \mathrm{~km}$ upstream of Lyon (Fig. 1). The overall slope of the river is $3.06 \mathrm{m.km} \mathrm{km}^{-1}$ and the catchment area is about $3700 \mathrm{~km}^{2}$. The investigated section extends over more than $40 \mathrm{~km}$ from the foot of the last major hydroelectric reservoir dam (Allement dam) to the confluence with the Rhone. This braided section flowing through a large floodplain is commonly called the "lower Ain river".

Temperature and flow were recorded in several places in the lower Ain river by "Electricite De France" over the period from 03/08/1980 to 20/07/1998. We chose data from the gauging station of Pont de Chazey (Fig. 1) because of its quite central location on this stretch. At this location, the catchment area is $3630 \mathrm{~km}^{2}$, the average annual flow is about $120 \mathrm{~m}^{3} \cdot \mathrm{s}^{-1}$ and the average annual water temperature is $11.34 \mathrm{C}$. Temperature and flow profiles are given on Figures 2 and 3. 


\subsection{Population censuing}

We used same data as used by Mallet [11]. We only remind here some of the main features of field experiments. The grayling population of the Gévrieux site (Fig. 1) was monitored over two periods, first in 1978-1985 (cohorts 1977 to 1981), and then from 1993 to 1998 (cohorts 1992 to 1998), by Capture-Marking-Recaptures or CMR [7, 8]. Grayling were collected by electrofishing [13] at low water levels, several times a year. All graylings were measured (total length at the nearest $\mathrm{mm}$ ), and scale samples were collected for age determination.

The spawning period starts with the regular increase of water temperature over $8 \mathrm{C}$. Spawning lasts about four weeks if reproduction activity is not disrupted by a drop of water temperature below 7C. Incubation time is around 210 day-degrees $[5,6,1]$, and emergence occurs some days later (10 days at 10C, $[5,1])$. So, the time-lapse between fertilisation and emergence is about 310 day-degrees.

\subsection{The life cycle graph of grayling}

The life cycle graph of grayling is rather short in this fast growing population significantly harvested by anglers (only few individuals exceed five years). It is considered at the scale of the year (from july to july). The age structure, rather than the size structure, appeared to be the most relevant according to available field data.

We selected the pre-breeding census model with a projection interval of five days [2]. This time step was chosen to provide a good account of temperature and flow fluctuations in the course of time. Five age groups were finally defined (Fig. 4):

- Age class 1: Young of the Year (denoted 0+), aged from 0 to 1 year.

- Age class 2: Juveniles (denoted 1+), aged from 1 to 2 years.

- Age class 3: Sub-Adults aged 2-3 years (denoted 2+), among which only a proportion is able to reproduce.

- Age class 4: Adults 3+ (aged 3-4 years), that represent the most effective proportion of the reproducer stock.

- Age class 5: Adults 4+ (aged 4-5 years) that are able to reproduce but are supposed to die immediately after.

On Figure 4, vital rates are denoted by $F_{i} \forall i=2,4$ for adult fecundity, and by $s_{i} \forall i=1,4$ for survival rates.

\subsection{Fecundity}

The reproduction takes place round about March. Fecundity is defined here as the number of emergent Young of the Year (YOY) per female; it takes into account both a balanced sex-ratio (1:1), and an emergence survival rate approximated to $60 \%$ [11]. Thus, we used the following values: 
- $F_{2}=370$ YOY per female

- $F_{3}=1084$ YOY per female

- $F_{4}=1555$ YOY per female

Here, in order not to start with a too complex model, we kept fecundity parameters constant between years despite a temperature or discharge effect might not be fully excluded certain years. We will come back later to this point.

\subsection{YOY survival rate}

The average five days survival rate of YOY is evaluated at about $96.5 \%$, what corresponds to an annual YOY survival rate about $7.4 \%$. Mallet [11] emphasized that this survival rate depends on discharge, especially on the maximum value of discharge (denoted $Q_{\max }$ ), observed during the 150 days following the deposition of the eggs. Thus, during the time step of reproduction, the five days survival of YOY is calculated as follows:

$$
s_{1}=0.965 \times c\left(Q_{\max }\right)
$$

with

$$
c\left(Q_{\max }\right)=\frac{Q_{\max }}{11.33 Q_{\max }-929.51}
$$

$c\left(Q_{\max }\right)$ is the reduction factor of YOY survival according to the maximum value of discharge $\left(Q_{\max }\right)$, as observed during the 30 time steps following reproduction. This relationship was estimated starting from survival values, obtained from a retro-calculation based on juvenile counts of the next year. Numerical values in equation (2.2) were chosen to obtain a range of the reduction factor from about 0.09 (corresponding to a survival rate of $\sim 8.7 \%$ ) when $Q_{\max } \simeq 1000 \mathrm{~m}^{3} . \mathrm{s}^{-1}$, to a maximum reduction factor of about 0.14 (corresponding to a survival rate of $\sim 13.5 \%$ ) when $Q_{\max } \simeq 200 \mathrm{~m}^{3} . \mathrm{s}^{-1}$ (Fig. 5). Hence:

$$
\lim _{Q_{\max } \rightarrow+\infty} c\left(Q_{\max }\right)=1 / 11.33 \Leftrightarrow \lim _{Q_{\max } \rightarrow+\infty} c\left(Q_{\max }\right) \simeq 0.088
$$

The rest of the year, the YOY survival rate is supposed to be constant and equal to $s_{1}=0.965$.

\subsection{Juvenile survival rate}

Thanks to the survival obtained by using CMR methods, Mallet [11] showed that the survival of juveniles depends at the same time on the flow $(Q)$, the temperature $(T)$, and the density of juveniles, $N_{j u v}$. Thus, we used the following equations:

$$
s_{2}=\left\{\begin{array}{l}
f_{1}(T) \quad \text { if } \quad N_{j u v} \leq 1000 \\
f_{1}(T) f_{2}(Q) \quad \text { if } \quad N_{j u v}>1000
\end{array}\right.
$$


The value 1000 corresponds to an average number of juveniles in summer in the river stretch considered.

Functions $f_{1}$ and $f_{2}$ are defined as below:

- $f_{1}$ is a decreasing logistic function of temperature $T$ (Fig. 6):

$$
f_{1}(T)=0.817+\frac{1-0.817}{1+e^{T-19}}
$$

Numerical values of equation (2.5) were chosen to obtain a minimal five days survival rate in the region of $81.7 \%$ (as observed by Mallet [11]), and an inflexion point of the curve $19 \mathrm{C}$ or thereabouts, a temperature corresponding to the slowing down of growth [12].

- $f_{2}$ is an increasing logistic function of discharge $Q$ (Fig. 7):

$$
f_{2}(Q)=0.817+\frac{1-0.817}{1+e^{6.5-0.1 Q}}
$$

As we saw before, YOY survival rate, $s_{1}\left(Q_{\max }\right)$, is a decreasing function of the maximum discharge occurring during the 30 time steps following reproduction, as only strong discharges have a negative impact on YOY survival [11]. Involved processes are probably their low swimming ability and energy reserves; in case of high discharge, YOY lose their refuge areas and nutritional resources, and are flushed away.

On the contrary, for juveniles, the survival rate, $s_{2}(Q)$, is an increasing function of discharge, as high discharges allow to extend the area of suitable habitats, and then to reduce intraspecific competition.

Numerical values of equation (2.6) were chosen as previous to obtain a minimal five days survival rate in the region of $81.7 \%$, and an inflexion point of the curve $65 \mathrm{~m}^{3} . \mathrm{s}^{-1}$ or thereabouts, around half of $150 \mathrm{~m}^{3} \cdot \mathrm{s}^{-1}$. Indeed, we considered that, when the discharge exceeds $150 \mathrm{~m}^{3} \cdot \mathrm{s}^{-1}$, the habitat suitability becomes maximal, mainly because it offers the maximum space for each individual.

\subsection{Adult survival rate}

The survival of adults is considered to only depend on temperature, according to the model given by the following equation:

$$
s_{i}=0.84+\frac{1-0.84}{1+e^{T-19}}
$$

with $i=3,4$.

As in the case of juvenile survival rate, numerical values were calibrated to obtain a minimal adult survival rate or so $84 \%$ (as observed by Mallet [11]), and an inflexion point of the logistic curve in the surroundings of $19 C$ (point of slowing down of growth [12]). 


\section{Matrix population modelling}

In order to take into account the fluctuations of temperature and discharge, the matrix model we propose depends on time, with a time step of five days. From temperature and discharge (Fig. 2 and 3), we rebuilt chronicles of temperature and discharge by step of five days over a period which extends from July, the $1^{\text {st }} 1980$ to July, the $1^{\text {st }} 1998$, i.e., 1319 time steps.

The reproduction takes place once per year around March, and the population dynamics can be described with the following equation:

$$
\mathbf{N}_{t+1}=\mathbf{L N}_{t}
$$

Where $\mathbf{N}_{t}$ is the population vector, and its $i^{t h}$ coordinate the number of individuals in the age-class $i$ at time $t$ :

$$
\mathbf{N}_{t}=\left(\begin{array}{lllll}
N_{1} & N_{2} & N_{3} & N_{4} & N_{5}
\end{array}\right)^{T}
$$

where ${ }^{T}$ denotes transposition.

The matrix $\mathbf{L}$ is differently defined according to whether it is the reproduction period $\left(\mathbf{L}_{r}\right)$ or not $\left(\mathbf{L}_{n r}\right)$. During the reproduction period, we also have a change in age-classes. Here follow both matrices:

$$
\begin{aligned}
\mathbf{L}_{\mathbf{r}}= & \left(\begin{array}{ccccc}
0 & 0 & F_{2} & F_{3} & F_{4} \\
s_{1} & 0 & 0 & 0 & 0 \\
0 & s_{2} & 0 & 0 & 0 \\
0 & 0 & s_{3} & 0 & 0 \\
0 & 0 & 0 & s_{4} & 0
\end{array}\right) \\
\mathbf{L}_{\mathbf{n r}}= & \left(\begin{array}{ccccc}
s_{1} & 0 & 0 & 0 & 0 \\
0 & s_{2} & 0 & 0 & 0 \\
0 & 0 & s_{3} & 0 & 0 \\
0 & 0 & 0 & s_{4} & 0 \\
0 & 0 & 0 & 0 & 0
\end{array}\right)
\end{aligned}
$$

Our time step in this model is equal to five days. Hence, $\mathbf{L}_{r}$ matrix runs on one single time step per year, whereas $\mathbf{L}_{n r}$ matrix runs during the 72 other time steps.

Parameters $s_{i}(i=1,4)$ are identical in $\mathbf{L}_{\mathbf{r}}$ and $\mathbf{L}_{\mathbf{n r}}$. Even in both cases, they play a different role, they have the same significance as a survival rate. $s_{i}$ is a survival rate corresponding only to survival in the case of $\mathbf{L}_{\mathbf{n r}}$. It corresponds to survival and to an additional change in the age-class in the case of $\mathbf{L}_{\mathbf{r}}$.

\section{Results}

\subsection{Reproduction dates and maximum flow estimates}

Based on field observations [11], and by taking into account that we averaged temperatures over five days, we considered that the beginning of the reproduction corresponds to the date at which 
the average water temperature is strictly higher than $8 C$. The maximum discharge is calculated from the daily data over the 150 days that follow the date of reproduction. These data are gathered in Table 1.

\subsection{Simulations}

Numerical simulations were performed under Mathematica 5®. Starting from the initial state of the population, as observed in mid-summer 1980:

$$
\mathbf{N}_{0}=\left(\begin{array}{lllll}
3.10^{5} & 1200 & 325 & 65 & 0
\end{array}\right)^{T}
$$

We simulated time fluctuations in the number of individuals per age-class. The size of the first age-class is practically impossible to estimate on field. So, we tested the sensitivity of our model to variations in this initial condition. No significant effect was observed, reinforcing our starting hypotheses.

In order to represent simulated data, we choose to show individual numbers each year at $\mathrm{Au}$ gust the first, in accordance with the collect of data on field. As shown on Figure 8, the whole number of adults, that encompasses three age-classes (squares), was almost the same than that of the single age-class of juveniles (triangles), until 1989. After this date, we note a sudden decrease in population size, after which the number of juvenile appears rather greater than the number of adults.

In the same way, the YOY population suffered a slump just after 1989 (Fig. 9). Besides, this slump is probably at the origin of the following low adult population size after 1989, as a too low number of YOY cannot allow a good restoration of juvenile and adult populations.

In order to validate our model, we compared the number of juveniles (age-class two, 1+ individuals) estimated in late July to those simulated at the beginning and end of this month. According to the model, July months with low discharges and subsequently high temperatures, 1994, 1995 and 1998 (Table 2), are inducing high mortality rates among juveniles (Fig. 10), whereas July months with high discharges and subsequently low temperatures, 1993, 1996 and 1997, ended in high survival rates. Field observations do not seem to fit very well with these predictions, but we have to consider that they were performed in rather hard experimental conditions because of, first, the low density of the population during the whole period, making the amount of recaptures rather limited, and, second, the bad hydraulic conditions disturbing the electric fishing campaigns when July was wet. Thus, the estimations based on CMR results (observations) must be considered as rough approximations, but they are not so much distant from the simulations and follow somewhat similar trends. Indeed, it is hard to expect an accurate numbering of the population at a given date in a strong decline period such as in July 1994, 1995 and 1998 : at a few day interval the number of individuals can change quickly. Thus, it would certainly be better to perform fishing operations before July, but then we usually have to face unsuitable discharges. This exemplifies how modeling might be useful for biologists having to deal with such a hard field context. 


\section{Discussion}

On the basis of previous results, our model is proved to be efficient in describing population dynamics of grayling in the Ain river. Major environmental factors like temperature and discharge seem to have been adequately identified to explain this dynamics. Hence, effect models, relating temperature and discharge to survival rates, have been included into a matrix population model. Advantages of this latter are mainly based on the fact that the population can be sub-divided into groups. Hence, vital rates can be considered as age-dependant, such as to take into account, for instance, the increasing fecundity with age.

As mentioned above, temperature is only implicitly taken into account on fecundity. But in a further development of this model we could envisage to include temperature effects on fecundity:

- During some particular years like summer 2003, excessive temperatures can stop ovogenesis leading to an absence of reproduction during the following spring (spring 2004 e.g.) [15]; but such a situation is too peculiar to be integrated in a common time model.

- A drastic drop in temperature during embryogenesis can reduce fecundity by impairing embryo survival rate; but such a case is statistically unlikely especially among cryophilic salmonids.

- At last, such a decrease in temperature can stop matings, but, usually in this case, they are only delayed for a few days or weeks.

Hence, the question of temperature as a factor influencing fecundity exists, but, in the case of grayling, its effects are not so frequent to be included in a predictive general model like the one we proposed.

The prevalence of temperature and discharge in the dynamics of the grayling population of the lower Ain River appeared very strong, considering many other factors might have impacted the population during this survey. Mortality events in adults were recorded some years, more or less related to high temperatures and low discharges, but not directly predicted by the model, and apparently with no more obvious direct effects on the dynamics. The shifting of the riverbed might have blurred the trends too by biasing the field results, the dimension and habitat profile of the section investigated changing progressively from year to year. It is also important to highlight that, despite the fish is free to enter or leave the river section considered, the good link between predictions and observations proved all the graylings from the lower Ain river to constitute a single population facing the same environmental conditions. Thus a 400-600 $\mathrm{m}$ large section can be representative of a $40 \mathrm{~km}$ river stretch. If this basic model is already functional at the lower Ain River level, many improvements can be envisaged to sharpen it in a more general perspective, and sensitivity analyses might be usefull for further developments.

Now the strong decline from 1989 is mainly determined by an increase in temperature [11], but the impacted cohorts had already been weakened in the previous years by bad hydraulic conditions at the $0+$ stage. It is nevertheless important to notice the lack of recover since, the thermal conditions remaining detrimental. It is then likely the population to stay scarce unless we can 
increase the survival rates in summer, mainly by manipulating discharge owing to the large reservoirs available upstream. However the amount of water required can be directly translated in a similar amount of money "wasted" for the electricity producers. A specific council gathering all the partners concerned has been created in order to manage this question at best, but that cannot change the climate itself.

The vital space exploited by fish populations in rivers is usually highly heterogeneous. River space can be viewed as an arborescent linear network with a very strong longitudinal gradient. In fact, the environmental conditions radically change upstream towards the downstream. Moreover, the apical compartments are numerous (all brooks in basin head) whereas the most downstream one is normally unique. Lastly, the river and its tributaries have a chronic instability due to the succession of floods and low water levels which never affect the various compartments at the same time and with the same intensity.

The exploitation of the compartment diversity is implicit in the life cycle of most of river fish species. It consists in significant migratory movements between compartments, in particular according to the stage of development. This phenomenon, particularly spectacular in amphibiotic species, stays almost the same for most of the other species. In fact, the degree of connectivity between the various compartments of the hydrographic network is an essential element in the dynamics of riverine fishes. In particular, it makes possible for fishes to refuge in neighboring compartments when the others are affected by a major disturbance. Thus, the majority of natural grayling populations in France do not depend on a single reach, but are based on one or more major confluences. It is thus probable that, in this species, populations depending on only one reach are exposed to extinction, and cannot endure for a long time. Due to damming of most of the intermediate water course, the vital space of the lower Ain grayling populations is severely constraint, with only two drying tributaries as possible spring nursery, and phreatic backwaters as possible thermic refuges in summer.

However, the main perennial impact of the human activities on the rivers is the deterioration of the environment by construction of dams or denaturation of certain reaches. The quantification of this effect on fish populations seems to be an insurmountable task, because of physical characteristics and dimensions of the whole environment. Hence, spatial modelling would be an elegant way to describe such an effect, by including biological strategies of the species.

From this point of view, we could imagine a spatial Leslie model $[3,4]$ with a realistic description of the geography of the river. The compartments favorable to the reproduction are now well known, and, according to the hydraulic chronicles, it should be possible to allot a different rate of success according to the year. An up to downstream gradient could be related to the water quality, leading to a spatial heterogeneity in survival rates. Lastly, the effect of the estival predation by fishermen (owing to fishing notebooks), and/or the effect of the winter predation by water birds (ornithological counting) could be introduced in the model, with the aim to develop a tool to help decision makers in the management of the environment. 
Table 1: Yearly reproduction date and maximum discharges in the 150 days period after reproduction in the Ain river, between 1981 and 1997, as used for YOY survival estimation.

\begin{tabular}{|c|c|}
\hline Reproduction date & Maximum discharge $\left(\mathrm{m}^{3} \cdot \mathrm{s}^{-1}\right)$ \\
\hline \hline $26 / 03 / 81$ & 232 \\
\hline $31 / 03 / 82$ & 1150 \\
\hline $21 / 03 / 83$ & 286 \\
\hline $09 / 04 / 84$ & 955 \\
\hline $04 / 04 / 85$ & 775 \\
\hline $04 / 04 / 86$ & 860 \\
\hline $04 / 04 / 87$ & 499 \\
\hline $19 / 03 / 88$ & 510 \\
\hline $09 / 03 / 89$ & 390 \\
\hline $17 / 02 / 90$ & 357 \\
\hline $04 / 03 / 91$ & 575 \\
\hline $18 / 03 / 92$ & 401 \\
\hline $18 / 03 / 93$ & 263 \\
\hline $03 / 03 / 94$ & 855 \\
\hline $16 / 02 / 95$ & 790 \\
\hline $22 / 03 / 96$ & 310 \\
\hline $25 / 02 / 97$ & 361 \\
\hline
\end{tabular}

Table 2: Average discharge and temperature during July from 1993 to 1998.

\begin{tabular}{|l||c|c|c|c|c|c|}
\hline July months & 1993 & 1994 & 1995 & 1996 & 1997 & 1998 \\
\hline Average discharge $\left(\mathrm{m}^{3} \cdot \mathrm{s}^{-1}\right)$ & 83 & 24 & 25 & 119 & 96 & 21 \\
Average temperature $(\mathrm{C})$ & 15 & 20.3 & 20.1 & 15.9 & 14.9 & 20.1 \\
\hline
\end{tabular}




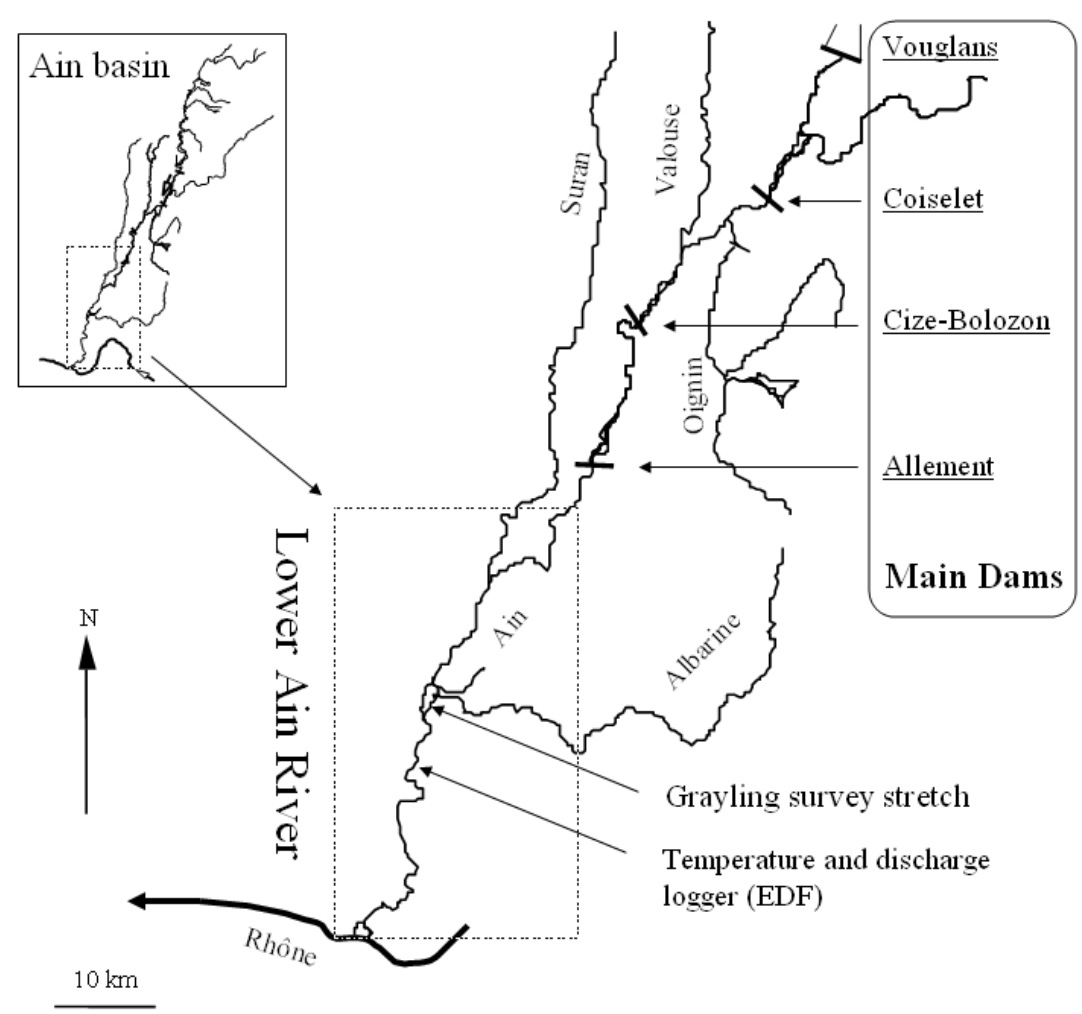

Figure 1: The Ain River in France and the study site location.

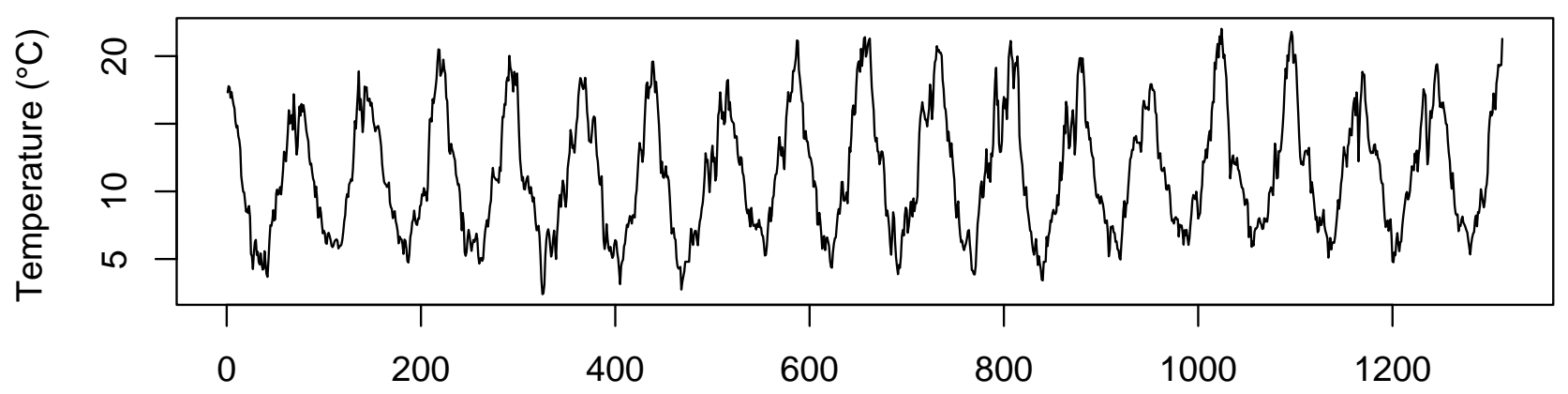

Figure 2: Temperature chronicle with a time step of five days between August 1980 and July 1998. 


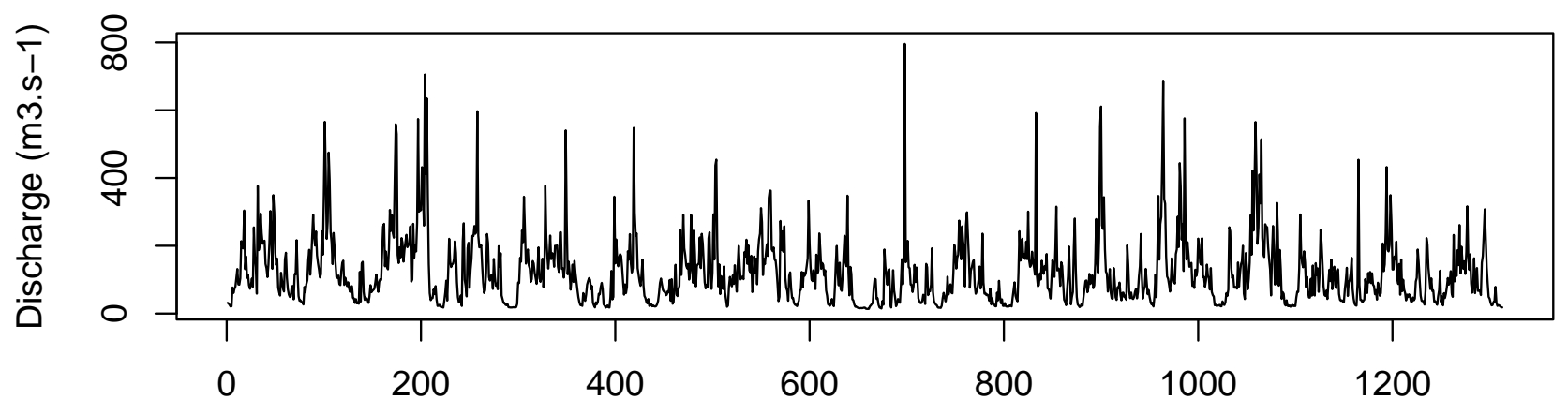

Figure 3: Discharge chronicle with a time step of five days between August 1980 and July 1998.

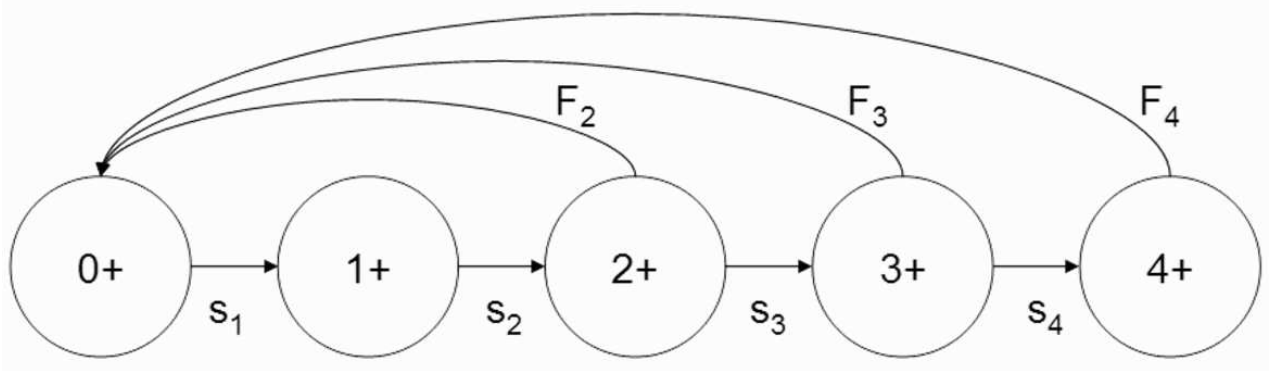

Figure 4: Life cycle graph of grayling. 


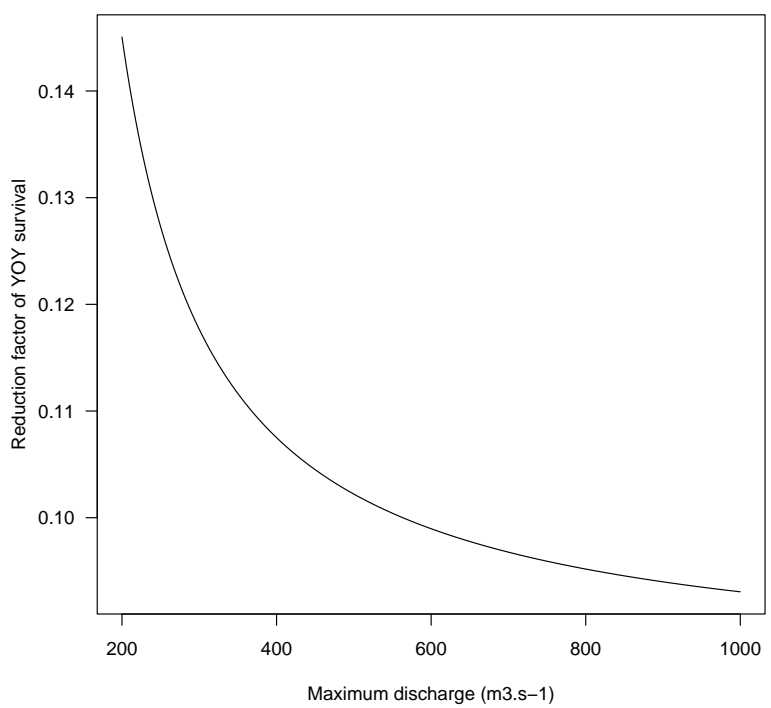

Figure 5: Graphical curve of the reduction factor of YOY survival rate (eq. (2.2)) related to the maximum discharge during the 150 days following the deposition of the eggs.

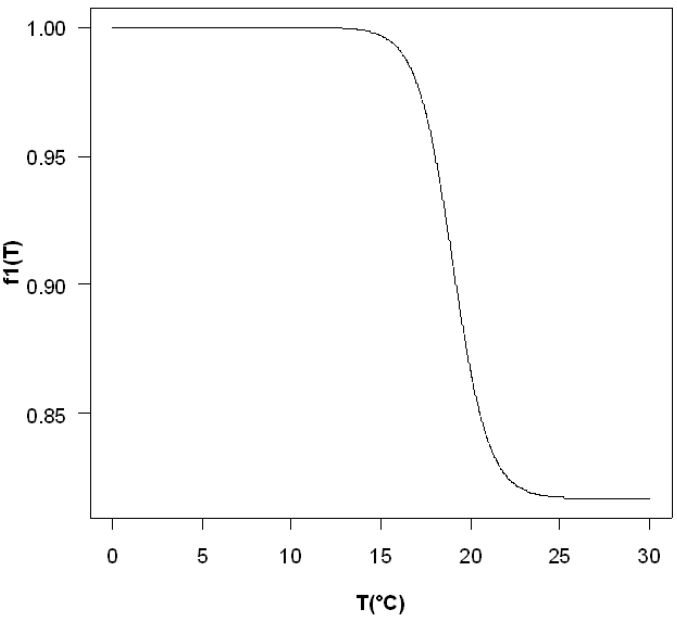

Figure 6: Graphical curve of $f_{1}(T)$ (eq. (2.5)), describing the relationship between juvenile five day survival rate and temperature. 


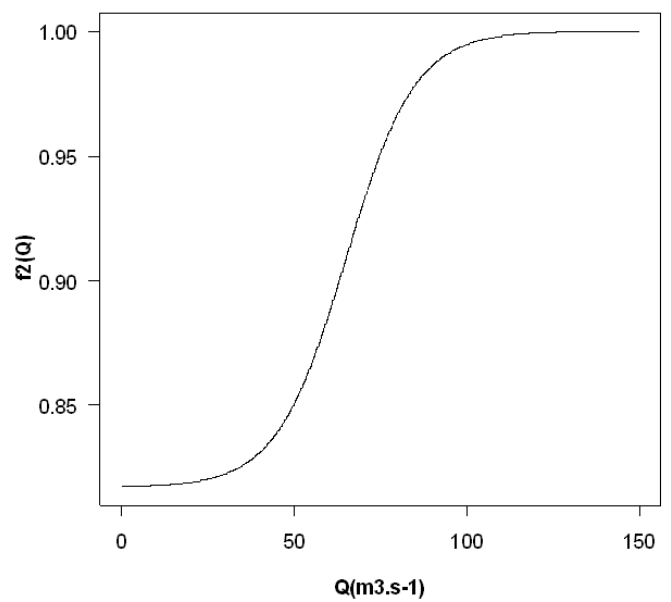

Figure 7: Graphical curve of $f_{2}(Q)$ (eq. (2.6)), describing the relationship between juvenile five day survival rate and discharge.

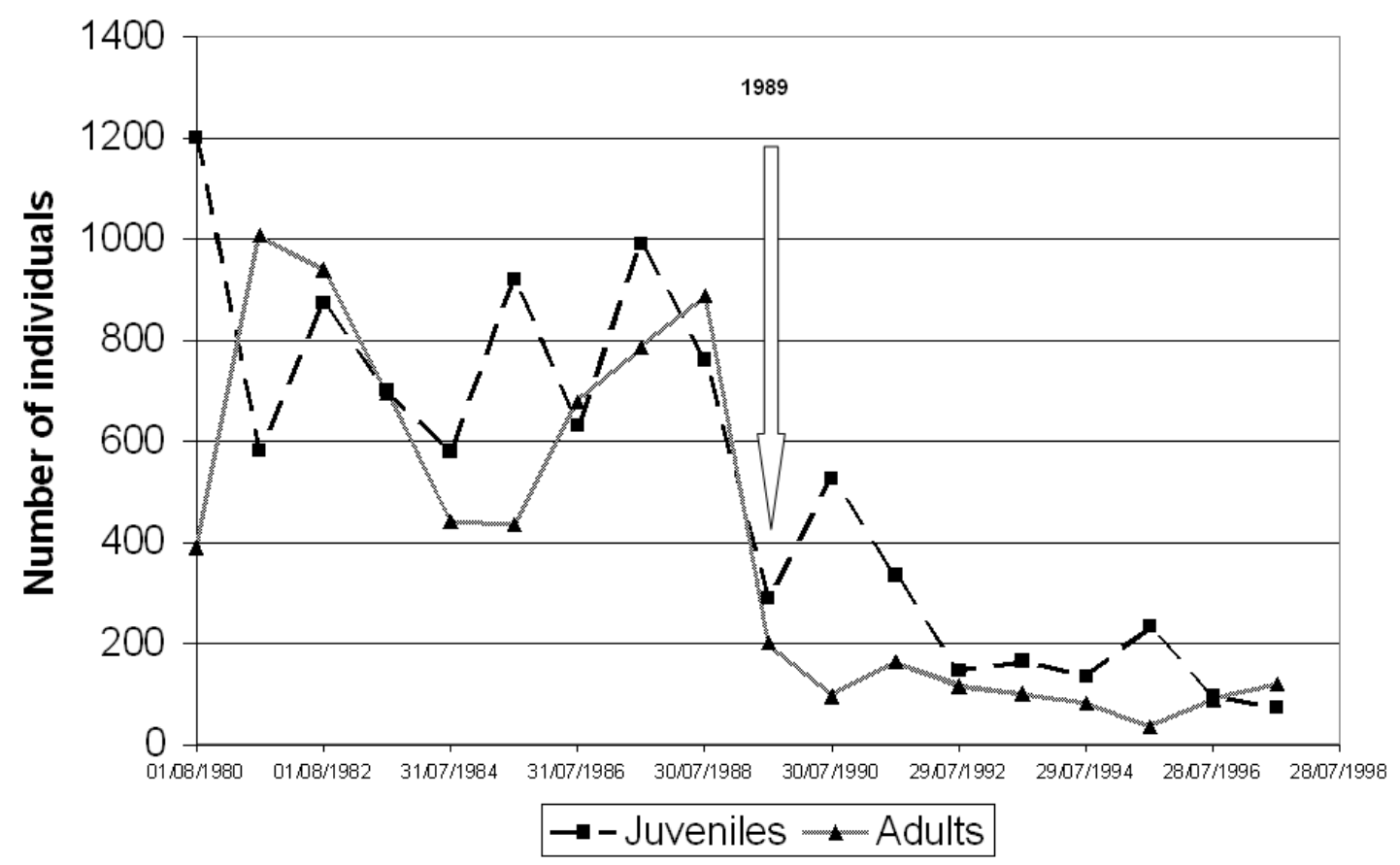

Figure 8: Population dynamics of graylings from 1980 to 1998, as simulated each year at August the first by the matrix population model (eq. 8): juveniles (squares) and adults (triangles). 


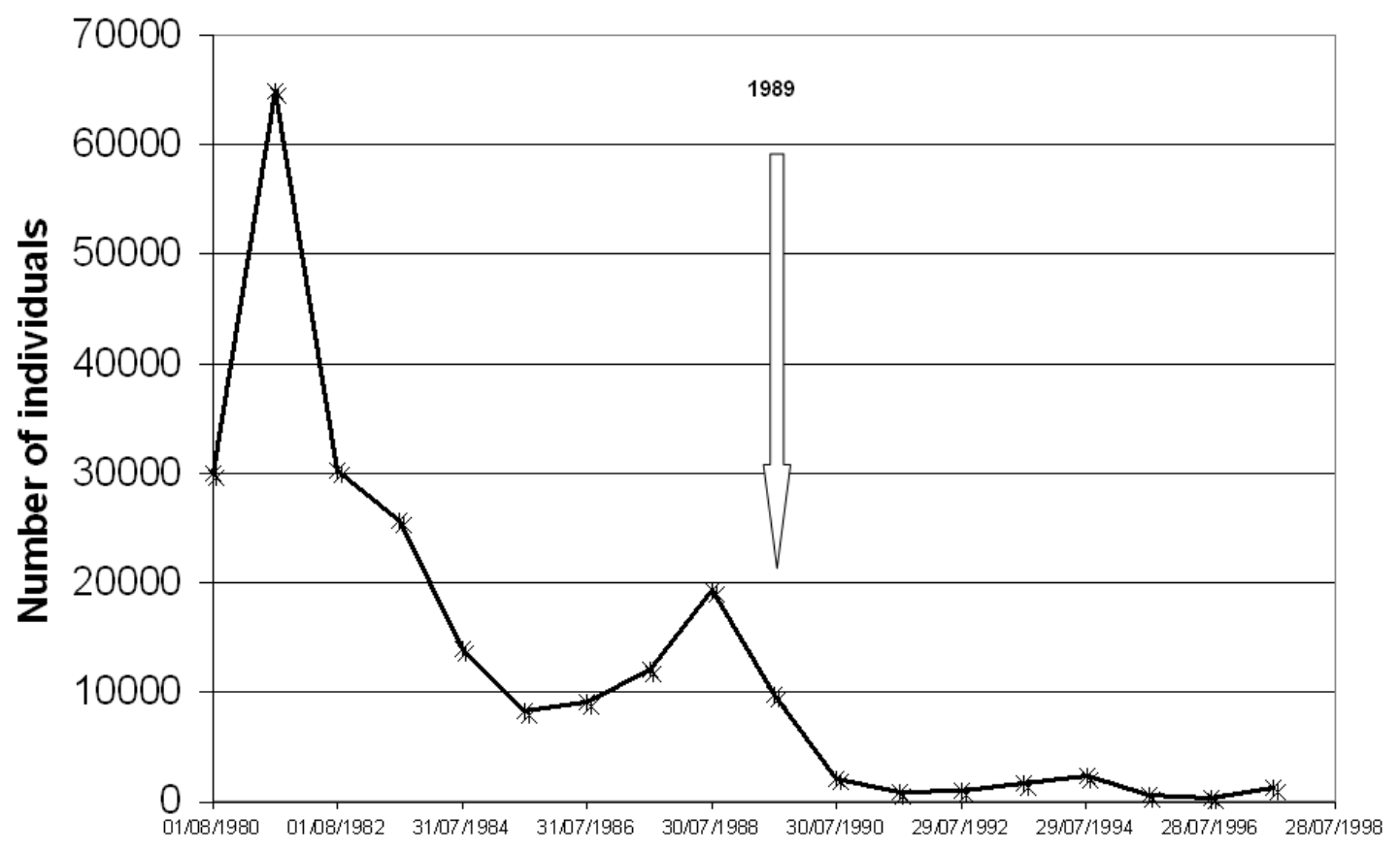

Figure 9: YOY population dynamics of graylings from 1980 to 1998, as simulated by the matrix population model (eq. (3.1)). 


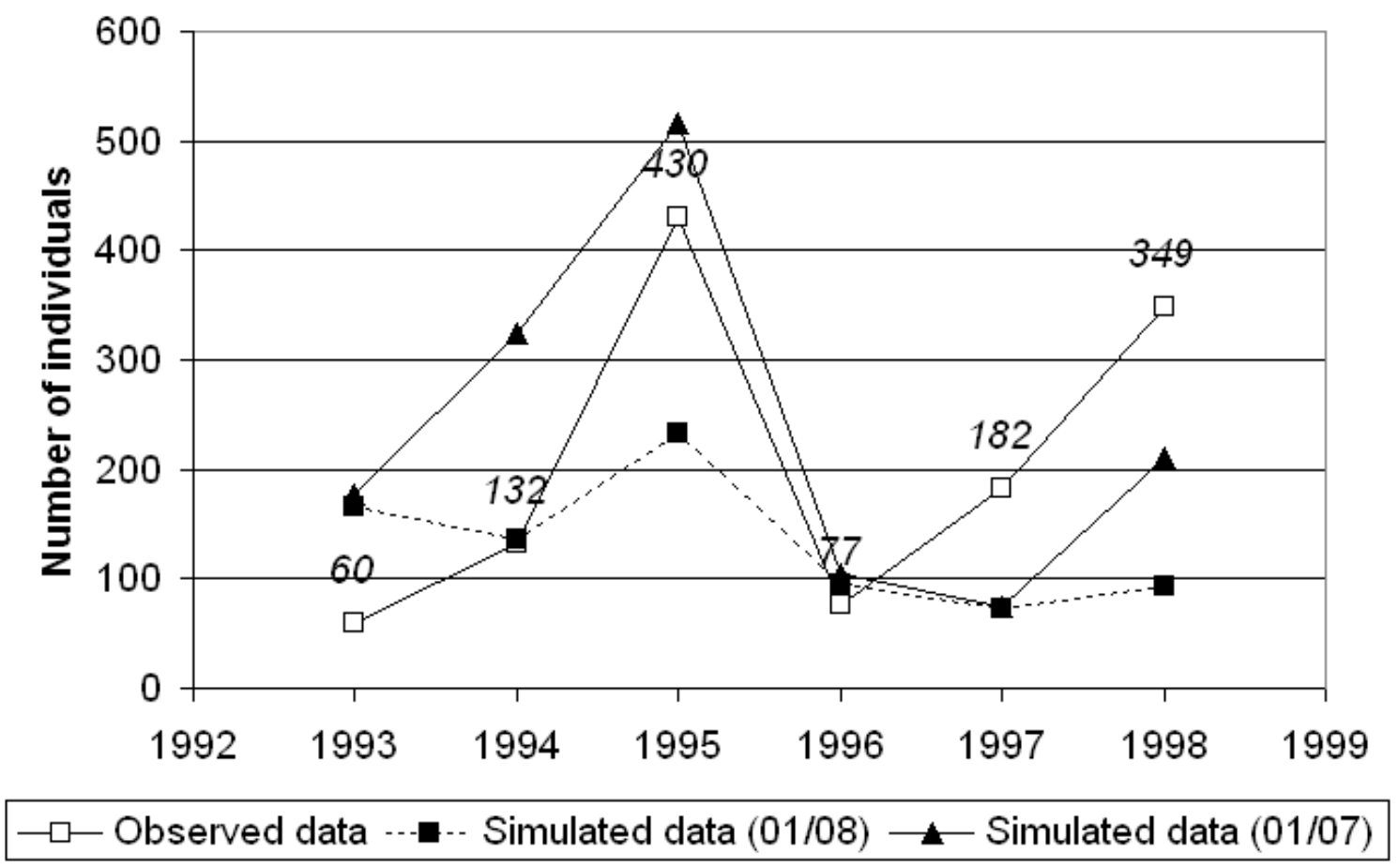

Figure 10: Observed (white squares), simulated at August, the first (black squares ), simulated at July, the first (black triangles) numbers of individuals, for the age-class two (1+ individuals). Numerical values correspond to observations. 


\section{Acknowledgements}

We are deeply grateful to "Electricité de France (EDF)" that supported a part of these investigations, both financially and technically, and to the French Fishing Service ("Conseil Supérieur de la Pêche") that initiated and sustained the initial works. We are very pleased to thank all the staff of the local angler society ("Union des Pêcheurs de la Rivière d'Ain"), who permanently provided a strategic help in the field works without which nothing would have been possible.

\section{References}

[1] A. Bardonnet, P. Gaudin, H. Persat. Microhabitats and diel downstream migration of young grayling (Thymallus thymallus 1). Freshwater Biology, 26 (1991), 365-376.

[2] H.Caswell. Matrix population models - construction, analysis, and interpretation. Sinsuer Associates, Sunderlands, Massachussets, 2nd edition, 2001.

[3] A. Chaumot, S. Charles, P. Flammarion, P. Auger. Do migratory or demographic disruptions rule the population impact of pollution in spatial networks? Theoretical Population Biology, 64 (2003), No. 4, 473-480.

[4] A. Chaumot, N. Milioni, A. Abdoli, D. Pont, S. Charles. First step of a modeling approach to evaluate spatial heterogeneity in a fish (Cottus gobio) population dynamics. Ecological Modelling, 197 (2006), No. 3-4, 263-273.

[5] O. D'Hulstere, J.C. Philippart. Observations sur le comportement d'éclosion et de postéclosion chez l'ombre commun Thymallus thymallus (1). Cahier d'Ethologie Appliquée, 2 (1982), No. 1, 63-80.

[6] M. Jungwirth, H. Winkler. The temperature dependence of embryonic developement of grayling (Thymallus thymallus), danube salmon (Hucho hucho), arctic char (Salvelinus alpinus) and brown trout (Salmo trutta fario). Aquaculture, 38 (1984), 315-327.

[7] J.D. Lebreton, K.P. Burnham, J. Clobert, D.R. Anderson. Modeling survival and testing biological hypotheses using marked animals: a unified approach with case studies. Ecological Monographs, 62 (1992), No. 1, 67-118.

[8] J.D.Lebreton, J.E. Hines, R. Pradel, J.D. Nichols, J.A. Spendelow. Estimation by capturerecapture of recruitement and dispersal over several sites. Oikos, 101 (2003), 253-264.

[9] P.H. Leslie. On the use of matrices in certain population mathematics. Biometrika, 33 (1945), No. 3, 184-212.

[10] P.H. Leslie. Some further notes on the use of matrices in population mathematics. Biometrika, 35 (1948), No. 3-4, 213-245. 
[11] J.P. Mallet. Recherche des facteurs de contrôle de la dynamique des populations d'ombre commun Thymallus thymallus (L.1758) de la basse rivière d'Ain. PhD thesis, Université Claude Bernard Lyon I, 1999.

[12] J.P. Mallet, S. Charles, H. Persat, P. Auger. Growth modelling in accordance with daily water temperature in european grayling (Thymallus thymallus 1). Canadian Journal of Fisheries and Aquatic Sciences, 56 (1999), No. 6, 994-1000.

[13] H. Persat. De la biologie des populations de l'ombre commun Thymallus thymallus (L.1758) à la dynamique des communautés dans un hydrosystème fluvial aménagé, Le Haut Rhône français. Eléments pour un changement d'échelle. $\mathrm{PhD}$ thesis, Université Claude Bernard Lyon I, 1988.

[14] H. Persat. Threatened populations and conservation of the european grayling, Thymallus thymallus (l.1758). In: Conservation of Endandegred Freshwater Fish in Europe. Eds. A. Kirchhofer, D. Hefti. Birkhaüser Verlag Basel, Switzerland, (1996), 233-247.

[15] V. Vey. Fonctionnement et gestion de la basse rivière d'Ain à l'étiage : bilan de la sécheresse 2003. Syndicat de la Basse Vallée de l'Ain. Blyes, 2004. 